coveries." This motion, after some discussion, was carried unanimously.

Dr. Schröder (Hamburg) then finished the communication begun at the previous meeting. Herren Abbe (Jena), Saffarik (Prague), Brubns (Leipzig), Winnecke (Strassburg), took part in the discussion on it. Prof. Oudemans (Utrecht) reported on the Gaussian object-glass of the Utrecht Observatory. Dr. Huggins (London) gave an account of his results in photographing star-spectra, and showed some of them to the meeting. Prof. Bruhns (Leipzig) exhibited drawings of nebula and neighbouring stars made by students of the University with small telescopes. Prof. Abbe (Jena) gave an elaborate account of his important theoretical and experimental researches in optics, followed by a discussion between him and Herren Förster and Winnecke. Prof. van de Sande Bakhuyzen (Leyden) explained his researches upon the dependance of the personal error in transit observations from the magnitude of the stars. Prof. Schönfeld (Bonn) reported on the progress of his "Durchmusterung" of the southern heavens. There is finished in observation at present about two-thirds of the whole work.

After a vote of thanks to the Prussian Government, the Royal Academy of Sciences, and the Berlin astronomers, the meeting of the International Astronomical Society was closed late in the afternoon.

A. WINNECKE

\section{INFLUENCE OF ELECTRICITY ON VEGETATION}

SEVERAL months ago, it will be remembered, $M$. Grandeau described to the Paris Academy experiments made by himself and M. Leclerc at Nancy and Mettray, whence it appeared that flowering and fructification are retarded and impoverished if plants are excluded from the influence of atmospheric electricity-as by being inclosed in a metallic cage, or being near trees or other objects which may carry off electricity of the air.

Recently $M$. Naudin has repeated the experiments referred to, but with other plants and in a different climate, and, without wishing to contradict the conclusions arrived at for tobacco and maize (the plants that had been experimented with), he is led to regard the declarations made as too general, inasmuch as his results are almost exactly opposite to those obtained by MM. Grandeau and Leclerc.

It was at Antibes, in the large botanical garden formed by the late Thuret (now Government property), that M. Naudin made his experiments. He bad an iron quadrangular cage made, covering a surface of fifty-one square decimetres, and about one metre in height; the frame carried points above (like small lightning conductors), and was covered with iron netting, the lozenge-meshes of this being $0.09 \mathrm{~m}$. long by $0.054 \mathrm{~m}$. broad (it intercepted more light than M. Grandeau's, but this is thought insignificant). The cage was placed in a kitchen garden, and the plants it was made to inclose were kidney beans, lettuce, tomato, and herbaceous cotton (the last alone being sown as seed). In the same garden, at 7 metres distance, plants as like the others as possible were planted, and cotton seeds of the same kind sown, but without a cage-cover. The soil was perfectly homogeneous throughout, and all parts of the plot vere equally exposed to sunlight, dew, and rain. The experiment began on May 25.

For a fortnight there appeared no sensible difference between the two portions ; but about the middle of June it was remarked that the plants of the cage were stronger than those in the open air, and this difference became more pronounced as time went on. The plants, indeed, progressed side by side in this sense, that the flowerings were absolutely contemporaneous in the plants of the same species ; and it was the same with formation and maturation of fruits. But it was quite otherwise with the quantity of vegetable matter produced in a given time and on the same extent of soil, and this difference was entirely in favour of the caged plants.

We may take the figures tabulated by M. Naudin for the tomato (examined August I4), as a good example of this :-

\begin{tabular}{|c|c|c|c|}
\hline & $\begin{array}{l}\text { Tomato in } \\
\text { open air. }\end{array}$ & & $\begin{array}{l}\text { mato under } \\
\text { the cage. }\end{array}$ \\
\hline Length of the principal stem ... & $0.80 \mathrm{~m}$ & $\cdots$ & rom. \\
\hline $\left.\begin{array}{l}\text { Total weight of the plant cut } \\
\text { at the level of the ground, } \\
\text { fruits included ... ... ... }\end{array}\right\}$ & $2.072 \mathrm{~kg}$ & $\cdots$ & $3^{\circ} 754 \mathrm{~kg}$ \\
\hline $\left.\begin{array}{c}\text { Number of ripe fruits and } \\
\text { green fruits of all sizes }\end{array}\right\}$ & 37 & $\cdots$ & 83 \\
\hline $\begin{array}{c}\text { Weight of the whole of the } \\
\text { fruit detached from } \\
\text { plant } \\
\ldots\end{array}$ & $\mathrm{I} \cdot 80 \mathrm{~kg}$. & $\cdots$ & $2.162 \mathrm{~kg}$. \\
\hline
\end{tabular}

The other plants gave a similar testimony in favour of the withdrawal of atmospheric electricity. Thus, the total weights of the bean plants were respectively $\mathrm{r} 42 \mathrm{gr}$. and $167 \mathrm{gr}$. ; and of the lettuce $337 \mathrm{gr}$. and $427 \mathrm{gr}$. The cotton plants were weakly (as there had been no watering), but their evidence was in the same line as that of the others.

The injurious influence, which, according to $\mathrm{M}$. Grandeau's theory, trees exert on plants in their neighbourhood, by withdrawing atmospheric electricity, is also considered by $M$. Naudin to be only a special case. Besides, it is easy to ascribe to this withdrawal what is merely the result of the shade cast by trees, and especially of the exhaustion and desiccation of the ground by their roots, which often extend to a great distance. On the other hand there are many plants which seek the neighbourhood of trees, and which even thrive only under their shadow, and these, probably, must be adapted to a diminution of atmospheric electricity. At the Villa Thuret, M. Naudin remarks, there are several lawns quite inclosed by trees (pines, firs, cypresses, \&c.), many of which are adult and of pretty good size. These lawns contain, besides their grass, thousands of anemones (A. pavonina, A. cyanea, A. stellati), some of pure race, others hybrid, whose flowers present all shades of red, rose, purple, white, and blue. The appearance is striking when the flowers come out in March or April. The flowering is not entirely contemporaneous throughout the lawn; it begins near the trees, and gradually extends to the middle of the lawn; the difference of time between these two extremes being twelve to fifteen days: Moreover, the anemones nearest to the trees, in addition to their relative precocity, are generally stronger and taller, and have broader, perhaps more brightly coloured corollas, than those in the middle of the lawn.

From the observations described, M. Naudin is disposed to think the question as to the influence of atmospheric electricity on plants is complex, and far from being decided as yet. This influence, in all probability, is modified first by the very essence of the species, which must behave, in regard to atmospheric electricity, as to other agents of vegetation, that is to say, in very diverse manners; then it is modified by climate, season, temperature, degree of light, dry or wet weather, perhaps alsa by the geolngical structure or mineralogical composition of the ground, the layers of which, suparficial or deep, may not be equally conductive of electricity. It is possible, lastly, that all tree species may not alike withdraw the electric effluves of the atmosphere, and this is a point necessary to be determined. Until these numerous and so obscure conditions of the problem before us are suffi. ciently known, we should regard as premature any conclusion which is applied to the whole, or even only to the generality of the vegetable kingdom.

\section{THE DIFFUSION OF LIQUIDS}

$\mathrm{T} \mathrm{T}$ is fortunate that various branches of the work with which Graham's name will always be connected are now attracting the attention of physicists. At the 